\title{
La España de los Bonaparte. Escenarios políticos y políticas escénicas
}

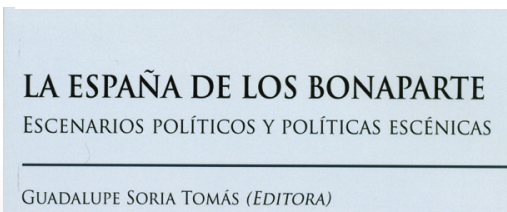

GUADALUPE SORIA TOMÁS (EDITORA)

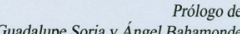

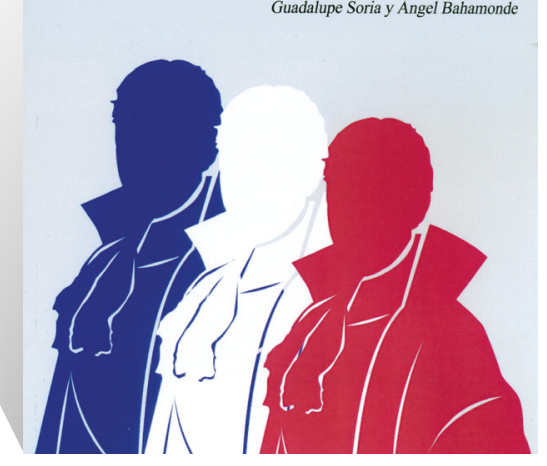

FICHA BIBLIOGRÁFICA

GUADAluPe SORIa TOMÁs (ED.), La España de los Bonaparte. Escenarios políticos y políticas escénicas, Madrid, Dykinson, 2015, 215 págs. ISBN 978-849085-619-2.

\section{Alba Gómez García Universidad Carlos III de Madrid}

El inesperado hallazgo, en los Archivos Nacionales de Francia (París), de un proyecto de decreto para los teatros durante el reinado de José Bonaparte, le brindó a Guadalupe Soria Tomás (Universidad Carlos III) la oportunidad de reflexionar sobre una España que (no) pudo ser; pues, aunque aquel proyecto no se llevó a la práctica, su actual descubrimiento invita a cuestionar ciertos tópicos y prejuicios que han sobrevivido arraigados en el imaginario popular hasta nuestros días, en torno al papel que desempeñó José I durante su corto reinado. Esta es la propuesta de La España de los Bonaparte, que introducen el historiador Ángel Bahamonde Magro y Guadalupe Soria, asimismo editora del volumen. 
Así, la profesora ha seguido interesándose por un ámbito bien conocido por ella, la modernización del espectáculo teatral en España entre los siglos XVIII y XIX, que abordó en La formación actoral en España. La Real Escuela Superior de Arte Dramático (1831-1857) (2010) desde uno de los necesarios puntales para que aquella lograra realizarse: la apertura de una Escuela de Declamación, imprescindible en la mejora de la formación de los cómicos anhelada por el pensamiento ilustrado.

La obra se estructura en tres bloques temáticos que abordan la política del reinado bonapartista, la construcción del imaginario cultural y el uso político del teatro, y cuya columna vertebral se rige por la intensa actividad propagandística que se desplegó en un breve espacio de tiempo. Siguiendo la definición de propaganda enunciada por Alejandro Pizarroso como "proceso de diseminación de ideas a través de múltiples canales» ${ }^{1}$ conducentes a informar y a persuadir al receptor favorablemente a los objetivos del emisor, La España de los Bonaparte se muestra voluntariosa para ofrecer una complejidad panorámica que rebasa los compartimentos estancos: la comprensión del relato histórico -al fin y al cabo, siempre interesado- pasa por conocer los cauces de control del flujo de la información, la dirección y la manipulación de esta y, sobre todo, los modelos de conducta. Por eso, aunque la disposición de los bloques temáticos ha segregado los trabajos en función de la especialidad de sus colaboradores -cuya nómina esclarece una cuidada y ambiciosa selección-, el volumen obtiene, por feliz resultado, una aproximación interdisciplinar que fluye sin sobresaltos por los escenarios que auspician la Historia, la Filología y los estudios teatrales.

De esta forma, la natural correlación de los distintos contenidos bien podría constituir el mayor acierto del libro. Bajo la teatral denominación «escenarios políticos», el primer bloque articula una reflexión en torno a la legitimidad de la Constitución de Bayona, reformista e ilustrada, y artífice de un Estado de derecho que garantizara la monarquía de un rey, empero, apenas sugerido. Con razón, el silencio promovido, tanto por los medios españoles como por los franceses, que envuelve a la figura del rey José, se adentra en el terreno de las construcciones culturales, de modo que el segundo bloque muestra oportunamente la manipulación del imaginario político y cultural propia de la Guerra de la Independencia. Para finalizar, «políticas escénicas» sintetiza los ángulos provistos por los bloques anteriores para trasladar la batalla a las tablas, una contienda abstracta cuya victoria -para la España bonapartista- se habría saldado con la implantación del modelo cultural francés. Así, bajo la asunción del arte escénico como una valiosa herramienta al servicio de la política, el tercer y último bloque revisa el proyecto reformista teatral durante el reinado josefino refiriendo el contexto propio del teatro español, un posible cuerpo legal para regirlo y un ejemplo de la circunstancial simbiosis de la propaganda y el teatro, producido por los patriotas españoles. Es quizás sobre el escenario teatral, a diferencia de los anteriores, donde el rey José cobre cierta y notable entidad en La España de los Bonaparte. Acaso no podía ser de otra forma, si se tiene en cuenta la comprensible diligencia con que el monarca legisló al respecto.

Manuel Moreno Alonso (Universidad de Sevilla), biógrafo de José Bonaparte y uno de los principales especialistas en España del mundo napoleónico, introduce y establece el mar-

1. A. Pizarroso Quintero, Historia de la propaganda, Madrid, 1990, 28. 
co contextual del resto de colaboraciones con «José Bonaparte, rey de las Españas». Carlos M. Rodríguez López-Brea (Universidad Carlos III de Madrid) firma un minucioso trabajo que se sumerge en el análisis comparado de los textos redactados en 1808 para los reinados de Nápoles y España. En «Las dos Bayonas del rey José», el profesor reconoce dos textos constitucionales diferenciados - es decir, conscientes de la realidad política a la que se destinaban- aunque mutuamente influidos; que, sin embargo, no incidieron en el desarrollo de posteriores constituciones. El autor, que no olvida la singular perspectiva de Napoleón, para quien las constituciones no eran sino instrumentos prácticos al servicio de sus intereses, se detiene especialmente en el caso español, en cuya redacción encuentra la factura de los notables españoles y no poca transigencia por parte del Emperador. Precisamente, estas especiales circunstancias en su gestación, marcaron una mayor complejidad y ambigüedad en la Bayona española con respecto a su homóloga napolitana. «La figura oficial del rey José Bonaparte en Francia durante la Guerra de la Independencia» amplía un estudio anterior del hispanista Jean-René Aymes (Universidad Paris 3-Sorbonne Nouvelle) para aproximarse a la figura que de José I y su gobierno difundieron los órganos oficiales del Imperio entre 1808 y 1813. El análisis se apoya en los diarios Le Menteur, Le Journal y Le publiciste, así como en La Gazzette Nationale y la Gaceta de Madrid: una riqueza documental cuya citación habría sido afortunada. El trabajo concluye con una imagen del monarca no del todo desfigurada sino, más bien, silenciada o aniquilada; apta, en fin, para mitigar las crecientes dificultades con las que debió lidiar su gobierno, y que paradójicamente equipara la práctica propagandística de los periodistas de París con la de los patriotas españoles. La colaboración del profesor Aymes no termina sin reclamar el tratamiento consciente y riguroso para un personaje que no ha gozado de la suficiente atención por parte de la historiografía española.

Ya en el segundo bloque, Juan Gutiérrez Cuadrado (Universidad Carlos III de Madrid) propone el análisis filológico de diversos textos en torno a tres intelectuales españoles determinantes en la elaboración del discurso de exaltación nacional decimonónico. Su excelente artículo "Pasión y Gloria de científicos afrancesados: Ezquerra del Bayo, Amorós, Orfila» descubre la manipulación de sus textos científicos con el fin de obtener réditos que revirtieran en el orgullo patrio. Por su parte, José Manuel Querol (Universidad Carlos III de Madrid) es autor de un trabajo de irreprochable factura, «La reivindicación de la Antigüedad en la literatura francesa y española en el período bonapartista», en el que recoge la influencia del modelo cultural clásico griego en la confección del imaginario histórico y político románticos a partir de textos tales como Viaje del joven Anacarsis, de Barthelemy o Las ruinas de Palmira, de Volney, tardíamente traducidos en España; donde, en cambio, el registro de un furor medieval apenas dará lugar a obras producidas al calor de la ensoñación histórica de la Antigüedad clásica.

El presente volumen acierta al contar con la colaboración de Ana $M^{a}$ Freire -su trabajo es indispensable para conocer el teatro durante la Guerra de la Independencia- «José Bonaparte y la reforma del teatro español», que repasa la política reformista cultural desarrollada diligentemente en este período. Este panorama general se completa con la aportación documental de Guadalupe Soria, la génesis de La España de los Bonaparte. En «Un nuevo proyecto de decreto para los teatros bajo el reinado de José I. Documentos de los Archives Nationales, Francia», la profesora estudia y pone a disposición del lector cinco interesantes documen- 
tos -hallados en los fondos del archivo privado de José I- que contribuyen a completar la relación de decretos, proyectos de reglamentos y otros borradores, que otros investigadores ya habían rescatado en diversos archivos institucionales. El proyecto de teatros, fechado en 1809, es anónimo -la profesora baraja los nombres de Mariano Luis de Urquijo o Moratín pero, en cualquier caso, detecta la influencia de ideas comunes entre los intelectuales ilustrados- y se concreta en dieciocho artículos, a su vez acompañados por la valoración, negativa, de un estrecho colaborador del monarca, el Consejero de Estado Jean Baptiste Félix FerriPisani. Muy atractivo es, por cierto, el documento $n^{\circ} 4$ que anexa la profesora al estudio, una misiva de Mariano Luis de Urquijo a José I, de 1810, que pone de manifiesto el interés del monarca por la regulación de los teatros en España. Por último, Fernando Doménech recoge el anverso de la batalla ideológica sobre el escenario en «Estrategias degradatorias en el teatro patriótico: El sermón sin fruto, de Félix Enciso Castrillón», donde revisa las estrategias difamatorias contra el invasor francés mediante la obra teatral que el propio Doménech edita e incluye como anexo. Curiosamente, el autor de la pieza subtitulada Josef Botellas en el Ayuntamiento de Logroño lo fue también de un manual para el desarrollo de su docencia en la Escuela de Declamación Española, del Real Conservatorio de Música de María Cristina, para la que asimismo contribuyó en su renovación. ${ }^{2}$

2. J. Álvarez Barrientos, "Acercamiento a Félix Enciso Castrillón”, en II Seminario de Historia de la Real Sociedad Bascongada de los Amigos del País, San Sebastián, 1989, 57-84. 